\title{
Toxocara Seroprevalence in Patients with Idiopathic Parkinson's Disease: Chance Association or Coincidence?
}

\author{
Tuncay Çelik, ${ }^{1}$ Yüksel Kaplan, ${ }^{2}$ Eser Ataş, ${ }^{3}$ Derya Öztuna, ${ }^{4}$ and Said Berilgen ${ }^{3}$ \\ ${ }^{1}$ School of Health, Adiyaman University, 02040 Adiyaman, Turkey \\ ${ }^{2}$ Department of Neurology, Faculty of Medicine, Inonu University, 44280 Malatya, Turkey \\ ${ }^{3}$ Department of Neurology, Faculty of Medicine, Firat University, 23119 Elazig, Turkey \\ ${ }^{4}$ Department of Biostatistics, Faculty of Medicine, Ankara University, 06100 Ankara, Turkey \\ Correspondence should be addressed to Tuncay Çelik; tuncay100@hotmail.com
}

Received 10 April 2012; Accepted 23 July 2012

Academic Editor: Luis I. Terrazas

Copyright @ 2013 Tuncay Çelik et al. This is an open access article distributed under the Creative Commons Attribution License, which permits unrestricted use, distribution, and reproduction in any medium, provided the original work is properly cited.

\begin{abstract}
Most cases of idiopathic Parkinson disease (IPD) are believed to be due to a combination of genetic and environmental factors. The purpose of this study is to investigate the relationship between toxocariasis and Parkinson disease (PD). Patients were selected from people who were admitted to the Movement Disorders Branch, Neurology Department of Elazığ University Faculty of Medicine Elazığ, Turkey. We studied specific IgG antibodies against Toxocara canis (T. canis) in 50 patients with idiopathic Parkinson and 50 healthy volunteers. We investigated the clinical history of three patients infected with T. canis. We also studied specific IgG antibodies against Toxoplasma gondii in these groups. Antibodies anti-Toxocara canis were found in 3 idiopathic PD $(6 \%)(P=$ 0.121 ) and antibody titer was not found in control. A patient had history of the presence of dog in current dog ownership. We did not detect any statistically significant association between T. canis and IPD. But, we believe that further comprehensive studies are required for understanding whether there is a causal relation between toxocariasis and PD. We didn't find possible association between Toxoplasma gondii and IPD $(P=0.617)$.
\end{abstract}

\section{Introduction}

The idiopathic form of Parkinson disease (IPD) is one of the most common neurodegenerative disorders. It is mainly characterized by a progressive and massive loss of dopaminergic (DA) neurons in the substantia nigra pars compacta $(\mathrm{SNpc})$, which leads to several clinical motor symptoms such as akinesia, rigidity, and resting tremor. The molecular pathways leading to these concomitant clinical alterations remain obscure, but it is believed that it may result from environmental factors, genetic causes, or a combination of the two [1]. The frequency of contact with infection agents in patients with IPD and the relationship between infections and clinical findings or pathogenesis of IPD are unclear. In relation to this, a few studies in the literature have drawn attention to the possible role of infectious agents in the pathogenesis of IPD [2-5].

Toxocariasis is caused by ingestion of the eggs of Toxocara canis (T. canis), a roundworm in dogs, puppies, and cats
[6]. Human who ingest T. canis eggs may remain unaffected or may manifest a mono- or multisystem disease with symptoms arising from larval invasion of different organs. Though neurological manifestations of T. canis larvae are rare, toxocariasis remains an important differential diagnosis of various neurological disorders [6, 7]. Neurological manifestations of toxocariasis have documented both the central and the peripheral nervous system. Dementia, behavioral disturbances, meningoencephalitis, myelitis, cerebral vasculitis, epilepsy, optic neuritis, radiculitis, affection of cranial nerves, lower motor neuron disease, and musculoskletal involvement have all been associated with neurotoxocariasis [6-12]. However, a possible relationship between $T$. canis infection and IPD has not been reported in the literature, but a few studies suggested a possible change in the neurotransmitter levels such as GABA, dopamine, serotonin, and monoamines in Toxocara-infected animals $[13,14]$. This observation drew our attention to a possible link between PD and T. canis infection. In order to further explore this association, we 
TABLE 1: Comparison of demographic and clinical characteristics between groups.

\begin{tabular}{|c|c|c|c|}
\hline Parameters & Patients $(n: 50)$ & Controls $(n: 50)$ & $P$ \\
\hline \multicolumn{4}{|l|}{ Gender } \\
\hline Male & $35(50.7)$ & $34(49.3)$ & \multirow{2}{*}{$P=0.824$} \\
\hline Female & $15(48.4)$ & $16(51.6)$ & \\
\hline Ages (years) & $75.0 \pm 73.92$ & $64.4 \pm 10.61$ & $P=0.21$ \\
\hline Duration of IPD (years) & $4.73 \pm 3.57$ (min: $1-\max : 17)$ & - & - \\
\hline Positive for Toxocara canis IgG antibodies & $3(6 \%)$ & $0(0 \%)$ & $P=0.121$ \\
\hline Positive for Toxoplasma gondii IgG antibodies & $9(18.0 \%)$ & $11(22.0 \%)$ & $P=0.617$ \\
\hline
\end{tabular}

evaluated the Toxocara antibodies in patient with IPD and compared the results with those of control group.

\section{Materials and Methods}

2.1. Patients and Evaluation. The patients were diagnosed with IPD according to the United Kingdom Parkinson's Disease Society Brain Bank Clinical Diagnostic Criteria in the Neurology Outpatient Clinic of the Medical Faculty of Elazığ University. All patients were randomly selected from the database of the neurology department. Control group were randomly selected among the healthy people who underwent a complete neurological examination to exclude the presence of neurological disorders and were matched to the case patients by age and gender. Demographic characteristics and information concerning factors possibly associated with $T$. canis infection were evaluated by a structured interview. We recorded data as follows: age, gender, duration of IPD, the presence of dog in the house, and clinic symptoms (dementia, epilepsy headache, fever, chronic urticaria, etc.). The study was performed in accordance with the Helsinki Declaration. All subjects signed informed consent after receiving a detailed explanation of the study procedures.

2.2. Serological Detection of Toxocara Canis Infection. Five milliliters blood samples were obtained from the cubital vein of both the patients and controls. The sera were separated from whole blood shortly after collection and was stored at $-20^{\circ} \mathrm{C}$ until the analysis. The sera were examined by ELISA T. canis IgG test (NOVATEC, Immundiagnostica $\mathrm{GmbH}$ ). In the next step, in order to detect possible involvement of Toxoplasma gondii in patients, the sera were also examined by ELISA Toxoplasma gondii IgG test (Cobas Core, Roche, Germany).

2.3. Statistical Assessment. Statistical evaluations were performed by using the SPSS 11.5 programme. For metric variables mean \pm standard deviation (minimum-maximum), for categorical variables frequency (percentage) was used as descriptive statistics. Student $t$-test was used to compare mean ages of groups. chi-square test was used to determine whether there was a difference between groups in terms of T. canis positivity. $P<0.05$ was considered as statistically significant.

\section{Results}

Fifty patients with IPD and fifty controls were enrolled in the study. The mean age of patients was $65.6 \pm 10.2$ (range: $43-81)$. Of the 50 patients, 32 (64\%) were males and 18 (36\%) were females. The mean duration of IPD was $5 \pm 4$ years (range: 1-17). The mean age of controls was $(65.6 \pm$ $30.4)$. Among the 50 controls, 29 (58\%) were males and 21 (32\%) were females. There were no statistically significant differences among the patients and controls subjects with respect to age and gender $(P=1.000$ and 0.818 , resp.). While 3 out of $50(6 \%)$ cases with IPD were positive for anti-T. canis IgG antibodies, all control subjects were negative. There were also no statistically significant differences between the rates of positivity between the IPD patient group and the control group $(P=0.121)$. In $9(18 \%)$ of the 50 patients, and in 11 (22\%) of 50 control group, anti-Toxoplasma gondii antibodies were detected $(P=0.617)$. Sociodemographic characteristics and clinical characteristics among groups are given in Table 1.

\subsection{Presentation of the Patients with Positive Toxocara Antibodies}

Patient 1. A 78-year-old male had a ten-year history of IPD. He had no history of presence of dog in the house and clinic symptoms of toxocariasis.

Patient 2. A 46-year-old male reported a history of IPD for two years. He had a dog in the house. But the patient reported no clinic symptoms of toxocariasis.

Patient 3. A 76-year-old male had an eight-year history of IPD. He had neither the presence of dog in the house nor clinic symptoms of toxocariasis.

Toxoplasma gondii IgG antibodies were negative in all patients.

\section{Discussion}

In this study, we investigated the $T$. canis IgG antibodies in patients diagnosed with IPD. Although Toxocara IgG antibodies were found in 3 IPD (6\%), all control subjects were negative. IPD is an age-related neurodegenerative disorder that is characterized by a slow and progressive degeneration of DA neurons in the SNpc combined with intracytoplasmic proteinaceous inclusions known as Lewy bodies. Despite an extensive research, the exact cause of IPD is not completely 
known, but important clues point at the involvement of some combination of genetic and environmental factors [5]. Several potential the pathogenic mechanisms of neuronal degeneration in IPD have been shown, including oxidative stress, neuroinflammatory processes, mitochondrial abnormalities, excitatory amino acids, a rise in intracytoplasmic free calcium, cytokines, and apoptotic processes. Recent studies have revealed an essential role for neuroinflammation that is initiated and driven by activated microglial and infiltrated peripheral immune cells and their neurotoxic products (such as proinflammatory cytokines, reactive oxygen species, and nitric oxide) in the pathogenesis of IPD [15]. Epidemiologic studies suggest that a number of environmental factors may increase the risk of developing IPD. These include exposure to well water drinking, farming, pesticides exposure (paraquat, organophosphates, and rotenone), herbicides, metals (manganese, copper, mercury, lead, iron, zinc, and aluminum), wood pulp mills, rural residence, diet, head trauma, and infections [5, 15]. Parkinsonian states have been described following viral encephalitis due to measles, Japanese B virus, Western equine virus, polio, epsteinbarr virus, cytomegalovirus, influenza A virus, and human immunodeficiency virus disease [5].

More recently, Miman et al. found Toxoplasma gondii IgG antibodies in IPD higher than controls. They speculated that there might be a possible association between Toxoplasma gondii and IPD and Toxoplasma infection may be involved in the pathogenic mechanisms of IPD [4]. But, our both studies did not detect any statistically significant association between T. gondii and PD [3].

The clinical presentations of toxocariasis have been documented both the central nervous system and the peripheral nervous system in the literature since 1951. More recently, the biochemical and immunopathological alterations in the brain in experimental neurotoxocariasis model have also been shown $[13,16]$. Othman et al. demonstrated significant increase in gene expression of proinflammatory cytokines and nitric oxide in the brains of Toxocara-infected mice especially in the chronic stage. Proinflammatory cytokines can be neuroprotective, but with sustained or overstimulated increase, they will have deleterious effects on the neurons [14]. They found also significant changes in neurotransmitter profile. They reported that $T$. canis infected mice demonstrated significantly decreased GABA, dopamine, monoamines, and serotonin levels compared with uninfected mice. However, norepinephrine levels were higher in infected mice in this study.

We could not find any published study which has evaluated the seroprevelance of toxocariasis in IPD patients. Besides, there are a few studies in Turkey about seroprevalence Toxocara. These studies show that the seroprevalence of toxocariasis varies between $2.6 \%$ and $51 \%$ in our country [17-23]. All of these studies except two reports have been done in childhood. One of these studies, Kaplan et al. showed that $T$. canis seroprevalence was $2.6 \%$ in healthy individuals in Elazı $\breve{g}$, an urban region in Turkey [17]. Another study has shown that the seroprevalence was $6 \%$ in students at veterinary college and $10 \%$ in people exposed to dogs [18].
We found seroprevelance of Toxocara as 7.1\% in patients with IPD and $0 \%$ in the controls. Despite the high anti-T. canis seropositivity found in our IPD patients, we did not detect any statistically significant differences between the rates of positivity between the IPD patient group and the control group. The relationship between anti-T. canis seropositivity and IPD may be chance association in these cases. On the other hand, the rate of anti-T. canis seropositivity in our patients increased nearly by a threefold when compared with study performed from Elazığ in healthy individuals. Furthermore, experimental models of neurotoxocariasis have also shown increased neuroinflammatory mechanisms and significant changes in neurotransmitter profile which all of neurotransmitters also play mainly role in IPD.

\section{Conclusion}

The present study suggest the possibility that the presence of the Toxocara IgG antibodies in patients diagnosed with IPD may extend beyond the chance. The pathogenic mechanisms involved in IPD remain incompletely understood. Based on the concept that IPD seems to be a multifactorial disease, genetic factors, oxidative stress, and neuroinflammatory processes have been implicated in its pathogenesis [24]. We believe that further comprehensive studies are required for understanding whether there is a causal relation between toxocariasis and IPD and/or the presence of the Toxocara IgG antibodies may be the possibility risk factor for IPD.

\section{References}

[1] J. B. Koprich, T. H. Johnston, P. Huot, M. G. Reyes, M. Espinosa, and J. M. Brotchie, "Progressive neurodegeneration or endogenous compensation in an animal model of Parkinson's disease produced by decreasing doses of alpha-synuclein," PLOS ONE, vol. 6, no. 3, Article ID e17698, 2011.

[2] M. Takahashi and T. Yamada, "Viral etiology for Parkinson's disease-a possible role of influenza A virus infection," Japanese Journal of Infectious Diseases, vol. 52, no. 3, pp. 89-98, 1999.

[3] T. Celik, O. Kamisli, C. Babur et al., "Is there a relationship between Toxoplasma gondii infection and idiopathic Parkinson's disease?" Scandinavian Journal of Infectious Diseases, vol. 42, no. 8, pp. 604-608, 2010.

[4] O. Miman, O. Y. Kusbeci, O. C. Aktepe, and Z. Cetinkaya, "The probable relation between Toxoplasma gondii and Parkinson's disease," Neuroscience Letters, vol. 475, no. 3, pp. 129-131, 2010.

[5] C. W. Olanow, P. Jenner, and N. A. Tatton, "Neurodegeneration and Parkinson's Disease," in Parkinson Disease and Movement Disorders, J. Jankovic and E. Tolosa, Eds., pp. 67-103, WilliamsWilkins, 3rd edition, 1998.

[6] J. Finsterer and H. Auer, "Neurotoxocarosis," Revista do Instituto de Medicina Tropical de Sao Paulo, vol. 49, no. 5, pp. 279-287, 2007.

[7] A. Nicoletti, V. Sofia, A. Mantella et al., "Epilepsy and toxocariasis: a case-control study in Italy," Epilepsia, vol. 49, no. 4, pp. 594-599, 2008.

[8] N. Z. Mikhael, V. J. A. Montpetit, and M. Orizaga, "Toxocara canis infestation with encephalitis," Canadian Journal of Neurological Sciences, vol. 1, no. 2, pp. 114-120, 1974. 
[9] P. J. Donovick and R. G. Burright, "The consequences of parasitic infection for the behavior of the mammalian host," Environmental Health Perspectives, vol. 73, pp. 247-250, 1987.

[10] J. Finsterer, V. Kallab, and H. Auer, "Neurotoxocariasis associated with lower motor neuron disease. Report of one case," Revista Medica de Chile, vol. 138, no. 4, pp. 483-486, 2010.

[11] I. H. Lee, S. T. Kim, D. K. Oh et al., "MRI findings of spinal visceral larva migrans of Toxocara canis," European Journal of Radiology, vol. 75, no. 2, pp. 236-240, 2010.

[12] N. Akao and N. Ohta, "Toxocariasis in Japan," Parasitology International, vol. 56, no. 2, pp. 87-93, 2007.

[13] A. E. Abdel Ghafar, S. E. Elkowrany, S. A. Salem, A. A. Menaisy, W. A. Fadel, and W. M. Awara, "Effect of some parasitic infection on neurotransmitters in the brain of experimentally infected mice before and after treatment," Journal of the Egyptian Society of Parasitology, vol. 26, no. 2, pp. 497-508, 1996.

[14] A. A. Othman, G. A. Abdel-Aleem, E. M. Saied, W. W. Mayah, and A. M. Elatrash, "Biochemical and immunopathological changes in experimental neurotoxocariasis," Molecular and Biochemical Parasitology, vol. 172, no. 1, pp. 1-8, 2010.

[15] K. U. Tufekci, S. Genc, and K. Genc, "The endotoxin-induced neuroinflammation model of Parkinson's disease," Parkinson's Disease, vol. 2011, Article ID 487450, 25 pages, 2011.

[16] N. P. Turrin and C. R. Plata-Salamán, "Cytokine-cytokine interactions and the brain," Brain Research Bulletin, vol. 51, no. 1, pp. 3-9, 2000.

[17] M. Kaplan, A. Godekmerdan, A. Kalkan, and A. Erensoy, "Toxocara canisSeroprevalence in Elazığ suburb in Turkey," in Firat University Journal of Health Science, vol. 13, pp. 51-54, 1999.

[18] M. G. Saglam, Evaluation of Toxocara canis occurrence by the ELISA method [Master of Philosophy thesis], Institute of Health Sciences, Istanbul University, 1999.

[19] N. Do®an, E. C. Dinleyici, O. Bor, S. O. Töz, and Y. Ozbel, "Seroepidemiological survey for Toxocara canis infection in the northwestern part of Turkey," Acta Parasitologica Turcica, vol. 31, no. 4, pp. 288-291, 2007.

[20] S. Yazar, O. Yaman, U. Cetinkaya et al., "Investigation of antiToxocara canisIgG antibodies in patients presenting at the Erciyes University Medical Faculty, Department of Parasitology," Acta Parasitologica Turcica, vol. 34, no. 1, pp. 24-26, 2010.

[21] Ç. Güngör, E. Çiftçi, and G. A. Akarsu, "Nedeni bilinmeyen karın ağrısı şikayeti olan çocuklarda Toxocaraantikoru prevalansı," Acta Parasitologica Turcica, vol. 23, no. 1, pp. 24-27, 1999 (Turkish).

[22] H. Oğuztürk and H and G. Sayg1, "Toxocara canis larvaları ile oluşan infeksiyonun ilköğretim okulu öğrencilerinde araştırılmas1," Acta Parasitologica Turcica, vol. 26, no. 4, pp. 409-414, 2002 (Turkish).

[23] O. Büyükbaba, E. Ozkan, and E. Buget, "Toxocara canis ve çocuklardaki seroprevalansının ELISA ile araştırılması,” Turkish Journal of Infection, vol. 10, no. 1, pp. 7-11, 1996 (Turkish).

[24] P. Scalzo, A. S. De Miranda, D. C. Guerra Amaral, M. De Carvalho Vilela, F. Cardoso, and A. L. Teixeira, "Serum levels of chemokines in parkinson's disease," NeuroImmunoModulation, vol. 18, no. 4, pp. 240-244, 2011. 

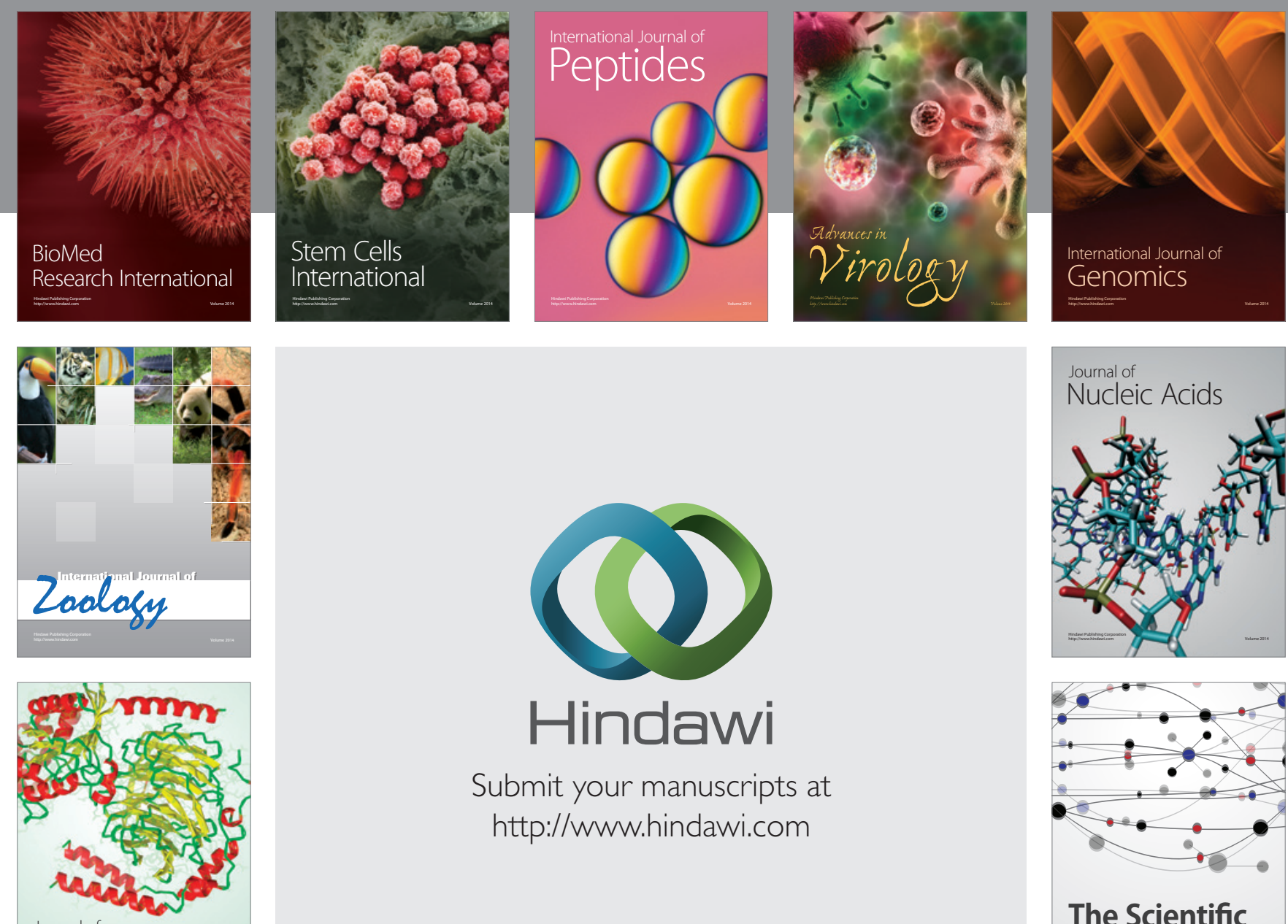

Submit your manuscripts at

http://www.hindawi.com

Journal of
Signal Transduction
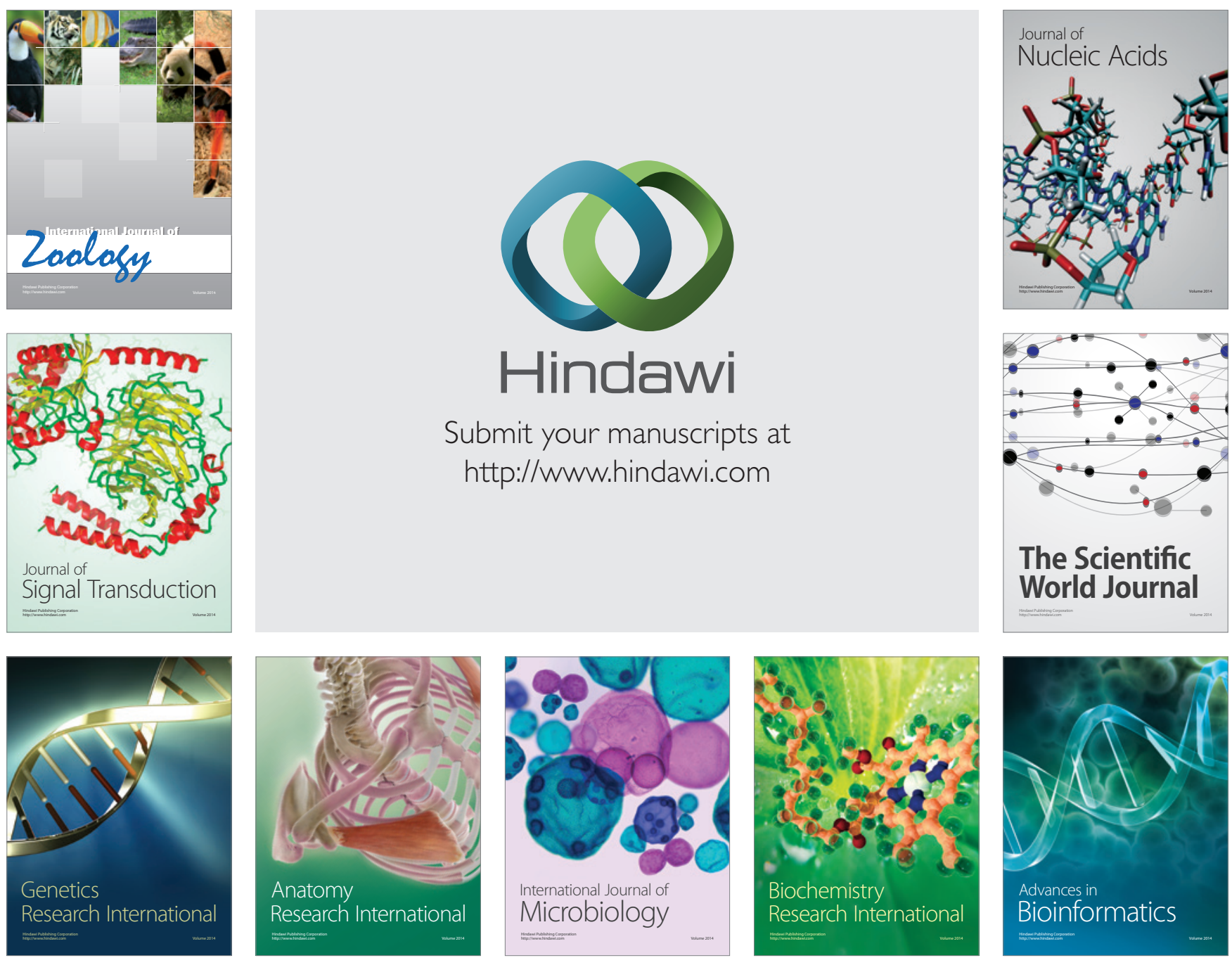

The Scientific World Journal
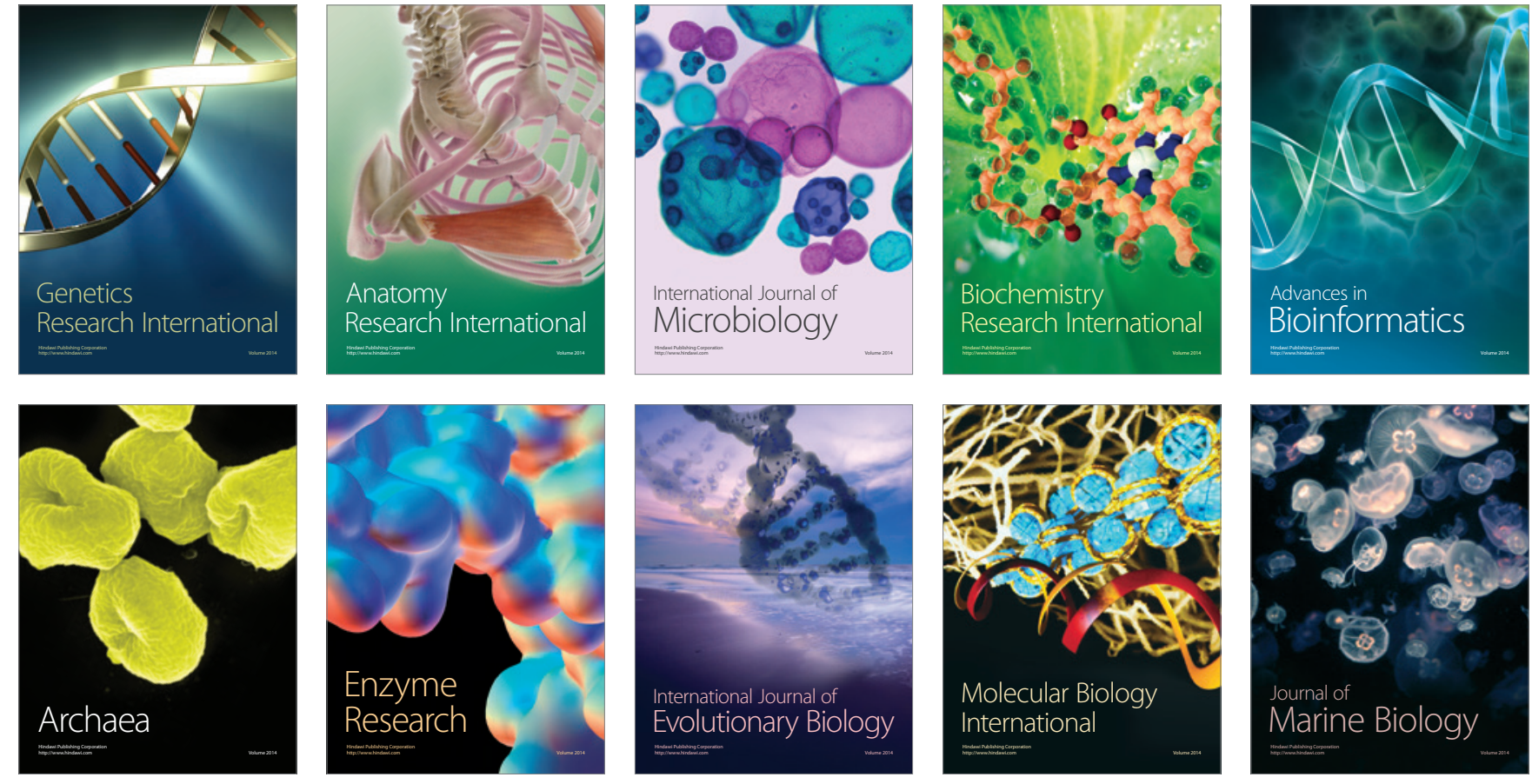